\title{
Pengaruh Metode Kangguru terhadap Penurunan Suhu Tubuh, Frekuensi Menyusu dan Durasi Tidur Bayi
}

\author{
Nikmah Jalilah Ritonga ${ }^{1, *}$, Riris Sitorus ${ }^{2}$, Susi Andriany Pulungan ${ }^{3}$ \\ ${ }^{1}$ Inkes Medistra Lubuk Pakam, Jl.Sudirman No.38, Lubuk Pakam 20512, Indonesia \\ ${ }^{2}$ Inkes Medistra Lubuk Pakam, Jl.Sudirman No.38, Lubuk Pakam 20512, Indonesia \\ ${ }^{3}$ Puskesmas Bandar Khalipah, JL.Puskesmas Pasar X, Deli Serdang 20371, Indonesia \\ ${ }^{1}$ ritonganikmah@yahoo.com*; ${ }^{2}$ rizriris@yahoo.com; ${ }^{3}$ suspul7@ gmail.com \\ * corresponding author
}

ARTICLE INFO

Article history

22-08-2021

$13-09-2021$

30-09-2021

Keywords

Kangaroo method,

Body temperature,

Feeding frequency,

Sleep duration

\section{ABSTRACT}

Immunizations sometimes have side effects once they are given to babies. DPT immunization is one that has a low-grade fever side effect and sometimes results in high fever and seizures. One of the efforts to treat fever in infants is the kangaroo method. Through this method, heat transfer occurs between mother and baby, increasing the frequency of breastfeeding which can meet the fluid needs of the feverish baby and facilitate the baby in increasing the duration of quiet sleep, less crying and less activity. The purpose of this study was to determine the effect of the kangaroo method on decreasing body temperature, feeding frequency and infant sleep duration. Sampling using Porbability Sampling with Simple Random Sampling technique, totaling 30 people and divided into 2 groups of 15 people each, namely the experimental and control groups. The results of the analysis are based on several assumptions of One way MANOVA, namely there is linearity between variables, the data is normally distributed, multicollinearity is not detected and the covariance matrix between groups is assumed to be the same as the Box'M value $\mathrm{p}=$ $0.006>0.001$. The results of the multivariate test showed that there was a significant difference between the two groups with a value of $F$ $(3.26)=49.334, p<0.001$; Wilk's $\Lambda 0.149, \eta p^{2}=0.851$, then the univariate results showed that group differences caused significant differences in body temperature, feeding frequency and sleep duration with $\mathrm{p}<0.001$. The results of the bonferroni correction further test showed that the average decrease in body temperature, feeding frequency and duration of infant sleep in the experimental group was better than the control group with $\mathrm{p}<0.001$. This study proves that the kangaroo method has an effect on decreasing body temperature, breastfeeding frequency and infant sleep duration after DPT immunization.

\section{Pendahuluan}

Imunisasi merupakan upaya yang dilakukan untuk meningkatkan imunitas didalam tubuh seseorang [1]. Melalui vaksin, imunitas anak dapat terbentuk sehingga angka morbiditas anak yang terpapar penyakit yang dapat mengganggu tumbuh kembang anak semakin menurun [2] Imunisasi terkadang memberikan efek samping setelah diberikan kepada anak. Efek samping yang muncul tergantung jenis imunisasi yang diberikan. Salah satu vaksin yang memiliki efek samping adalah DPT, dan efek samping yang muncul seperti demam ringan, pembengkakan dan rasa nyeri di area penyuntikan, dan terkadang terjadi reaksi yang lebih berat seperti demam tinggi dan kejang [3].

Secara garis besar, penatalaksanaan demam dilakukan dengan cara farmakologis dan nonfarmakologis. Intervensi farmakologis berupa analgesik non-narkotik yang digunakan secara 
luas untuk mengendalikan demam, peradangan dan nyeri dalam derajat ringan antara lain asetaminofen, aspirin serta obat anti-inflamatorik nonsteroid lainnya[4,5] namun pemberian pereda nyeri secara farmakologis juga terkadang memberikan efek samping dan menimbulkan ketidaknyamanan pada pasien [6]. Intervensi secara nonfarmakologis dinilai sebagai pereda nyeri yang memiliki resiko atau efek samping yang rendah [7].

Salah satu tindakan non farmakologis dalam penanganan demam adalah metode kangguru [8]. Melalui metode kangguru akan terjadi perpindahan panas antara ibu dan bayinya. Bayi yang mengalami hipotermi akan terjadi perpindahan panas dari suhu tubuh ibu ke bayi, dan sebaliknya bayi yang mengalami hipertermi juga memindahkan suhu tubuhnya ke ibu melalui proses konduksi [10].

Perawatan metode kangguru juga efektif dalam meningkatkan frekuensi menyusu bayi sehingga dapat memberikan kecukupan cairan pada bayi yang mengalami demam. Hal ini disebabkan karena adanya kontak langsung kulit ibu dan bayi, dan kondisi ini mirip dengan keadaan di dalam rahim sehingga menimbulkan rasa nyaman dan bayi menjadi lebih sering menyusu [10]. Selain kecukupan cairan, pengelolaan demam dapat dilakukan dengan mengusahakan agar bayi tidur atau istirahat [6]. Efek dari metode kangguru dapat memfasilitasi bayi dalam meningkatkan frekuensi dan durasi tidur yang tenang, sedikit waktu menangis dan tingkat aktivitas yang lebih rendah. Selama perawatan metode kangguru menunjukkan hasil yang lebih maksimal sesuai dengan kebutuhan tidurnya [11].

\section{Metode}

Penelitian ini merupakan penelitian kuantitatif yang menggunakan studi quasi experiment dengan desain post test with control group dengan melakukan observasi pada kelompok yang diberikan intervensi dan membandingkan hasil observasi dengan kelompok kontrol. Populasi dalam penelitian ini adalah bayi usia 2-6 bulan yang mendapatkan imunisasi DPT di wilayah kerja Puskesmas Bandar Khalipah.

Pengambilan sampel dalam penelitian ini menggunakan Porbability Sampling dengan teknik Simple Random Sampling, yaitu teknik pengambilan sampel yang dilakukan secara acak sederhana, dinama setiap anggota populasi dalam penelitian memiki kesempatan yang sama untuk terpilih menjadi sampel penelitian yang berjumlah 30 orang, yang terdiri dari 2 kelompok masingmasing berjumlah 15 orang yaitu kelompok Intervensi (Melakukan Metode kangguru) dan kelompok kontrol (tidak melakukan metode kangguru). Selama proses penelitian berlangsung tidak ada responden yang drop out. Seluruh sampel penelitian kooperatif mengikuti proses penelitian dengan baik dankuesioner yang diberikan dapat terisi 100\%.Penelitian ini juga sudah lolos uji etik (mendapat persetujuan etik) penelitian yang dibuktikan dengan sertifikat etik dari Komisi etik penelitian Kesehatan Fakultas Keperawatan Universitas Sumatera Utara pada tanggal 01 Juni 2021 dengan nomor Reg 2306/VI/SP/2021.

\section{Hasil dan Diskusi}

\section{a. Uji Asumsi One Way MANOVA}

Grafik 1. Analisis Linieritas data menggunakan scatter Plot
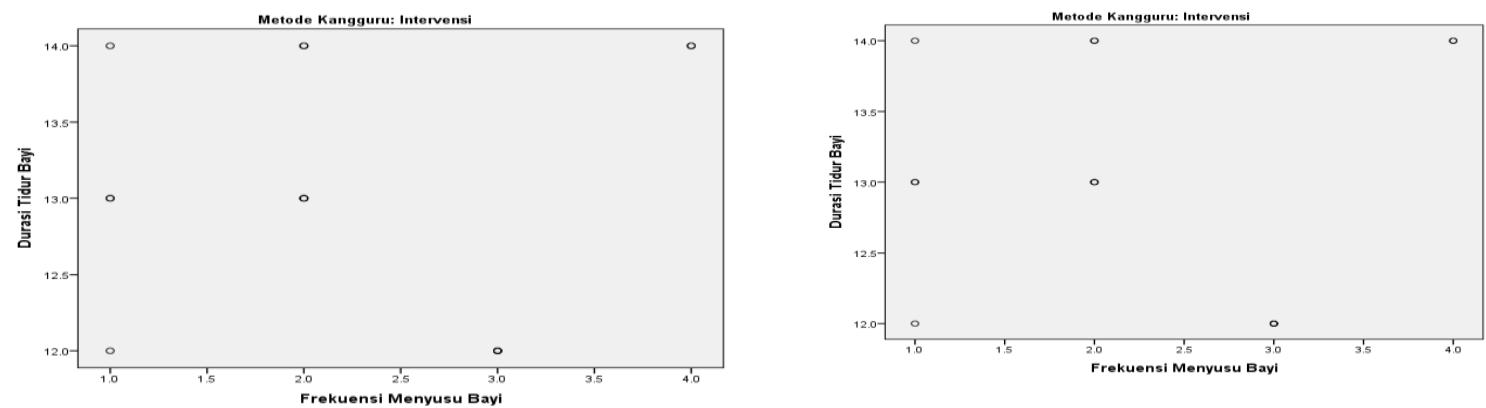

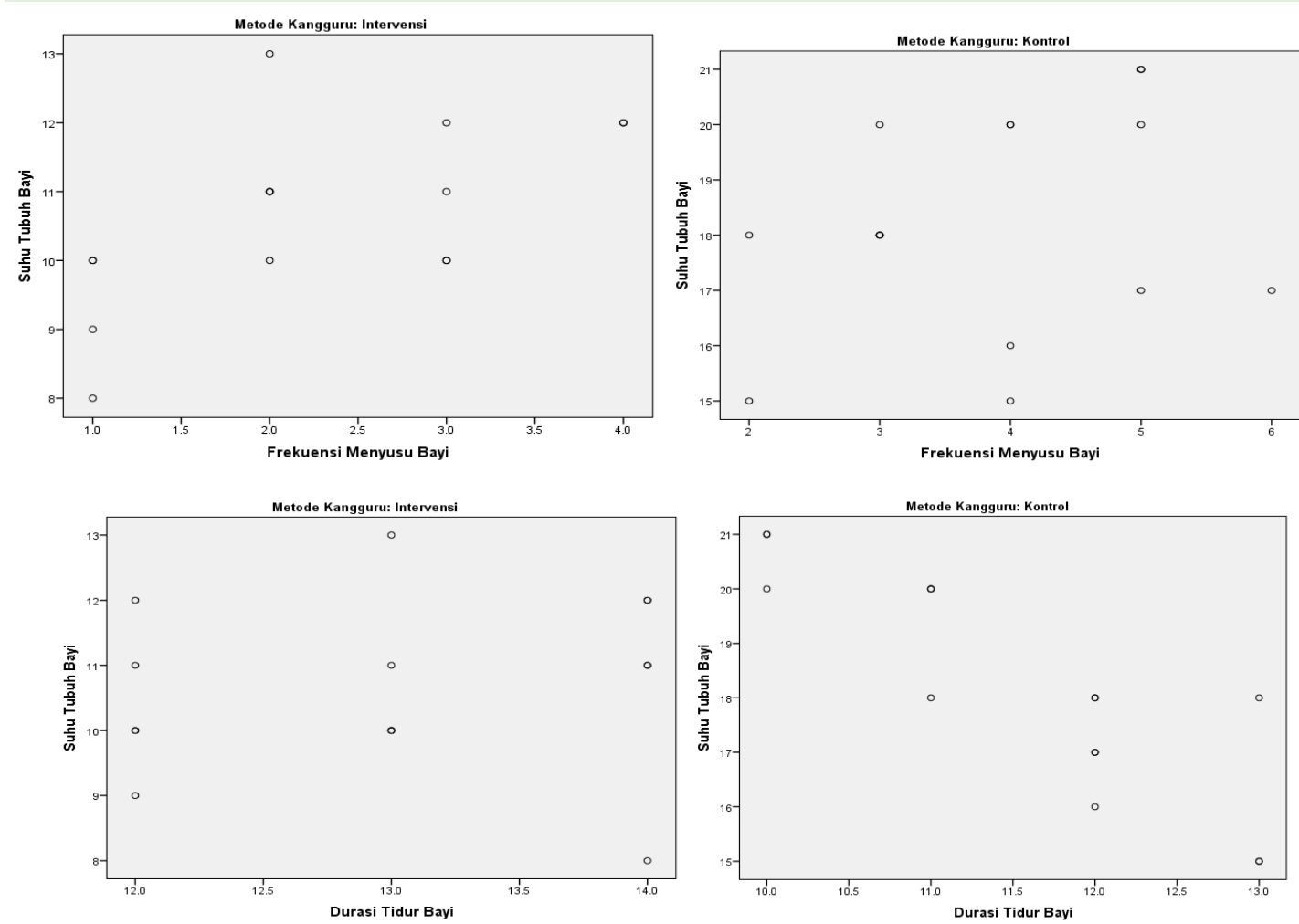

Scatter plot dihasilkan untuk menganalisis kelinieritasan hubungan antara suhu tubuh, frekuensi menyusu dan durasi tidur di masing masing kelompok. Hasil scatter pada grafik 1 menunjukkan bahwa suhu tubuh, frekuensi menyusu dan durasi tidur memperlihatkan hubungan yang linier baik pada kelompok intervensi maupun kelompok kontrol.

Tabel 1. Uji normalitas data menggunakan Kolmogorov smirnov

\begin{tabular}{llccccc}
\multicolumn{9}{c}{ Tests of Normality } \\
\cline { 2 - 6 } & Metode & \multicolumn{2}{c}{ Kolmogorov-Smirnov $^{\text {a }}$} & \multicolumn{2}{c}{ Shapiro-Wilk } \\
\cline { 2 - 6 } & Kangguru & Statistic & df & Sig. & Statistic & df \\
\hline \multirow{2}{*}{ Suhu Tubuh Bayi } & Intervensi & .169 & 15 & $.200^{*}$ & .950 & 15 \\
Frekuensi Menyusu & Kontrol & .205 & 15 & .090 & .915 & 15 \\
Bayi & Intervensi & .202 & 15 & .101 & .885 & 15 \\
Durasi Tidur Bayi & Kontrol & .167 & 15 & $.200^{*}$ & .931 & 15 \\
& Intervensi & .215 & 15 & .061 & .805 & 15 \\
& Kontrol & .203 & 15 & .095 & .889 & 15 \\
\hline
\end{tabular}

Uji Kolmogorov smirnov dilakukan untuk menganalisis kenormalan data suhu tubuh,frekuensi menyusu dan durasi tidur di setiap kelompok penelitian. Hasil analisis pada tabel 3.1 menunjukkan bahwa data suhu tubuh di kelompok intervensi $[W(15)=0.950, p=0.200]$, kelompok kontrol $[W$ $(15)=0.915, p=0.090]$ terdistribusi normal. Data frekuensi menyusu pada kelompok intervensi $[W$ (15) $=0.885, p=0.101]$, kelompok kontrol $[W(15)=0.931, p=0.200]$ terdistribusi normal. Data durasi tidur bayi pada kelompok intervensi $[W(15)=0.805, p=0.061]$, kelompok kontrol $[W(15)$ $=0.889, p=0.095]$ juga terditribusi normal.

Tabel 2. Analisis asumsi multikolinearitas data

\begin{tabular}{lrrrr}
\hline Model & R & R Square & Adjusted R Square & $\begin{array}{c}\text { Std. Error of the } \\
\text { Estimate }\end{array}$ \\
\hline 1 & $.677^{\mathrm{a}}$ & .458 & .418 & 1.040 \\
\hline
\end{tabular}

Hasil analisis pada tabel 2. di atas menunjukkan bahwa suhu tubuh, frekuensi menyusu dan durasi tidur bayi saling berhubungan dan kekuatan hubungannya pada kategori moderat $\left(R^{2}=0.458\right.$ $<0.8$ ). Dengan demikian gejala multikolinearitas tidak terdeteksi sehingga analisis one way MANOVA dapat dilanjutkan. 
Tabel 3. Analisis asumsi homogenitas Data

Box's Test of Equality of Covariance

Matrices $^{\mathbf{a}}$

\begin{tabular}{lr}
\hline Box's M & 20.518 \\
\hline F & 3.019 \\
df1 & 6 \\
df2 & 5680.302 \\
Sig. & .006 \\
\hline
\end{tabular}

Tabel 3. di atas adalah analisis asumsi homogenitas data penelitian dan didapatkan hasil nilai Box'M sebesar $20.518(p=0.006<0.001)$. Dengan demikian matiks kovarian antar kelompok diasumsikan sama atau homogen.

\section{b. Analisis Uji Hipotesis Penelitian (One Way MANOVA)}

Tabel 4. Analisis Multivariate

Multivariate Tests ${ }^{\mathrm{a}}$

\begin{tabular}{|c|c|c|c|c|c|c|c|}
\hline Effect & & Value & $\mathrm{F}$ & $\begin{array}{l}\text { Hypothesis } \\
\text { df }\end{array}$ & Error $\mathrm{df}$ & Sig. & $\begin{array}{c}\text { Partial Eta } \\
\text { Squared }\end{array}$ \\
\hline \multirow{4}{*}{ Intercept } & Pillai's Trace & .998 & $4568.710^{b}$ & 3.000 & 26.000 & .000 & .998 \\
\hline & Wilks' Lambda & .002 & $4568.710^{\mathrm{b}}$ & 3.000 & 26.000 & .000 & 998 \\
\hline & Hotelling's Trace & 527.159 & $4568.710^{\mathrm{b}}$ & 3.000 & 26.000 & .000 & .998 \\
\hline & $\begin{array}{l}\text { Roy's Largest } \\
\text { Root }\end{array}$ & 527.159 & $4568.710^{\mathrm{b}}$ & 3.000 & 26.000 & .000 & 998 \\
\hline \multirow{4}{*}{$\begin{array}{l}\text { Metode_ } \\
\text { Kanggur } \\
\text { u }\end{array}$} & Pillai's Trace & .851 & $49.334^{b}$ & 3.000 & 26.000 & .000 & .851 \\
\hline & Wilks' Lambda & .149 & $49.334^{\mathrm{b}}$ & 3.000 & 26.000 & .000 & .851 \\
\hline & Hotelling's Trace & 5.692 & $49.334^{\mathrm{b}}$ & 3.000 & 26.000 & .000 & .851 \\
\hline & $\begin{array}{l}\text { Roy's Largest } \\
\text { Root }\end{array}$ & 5.692 & $49.334^{\mathrm{b}}$ & 3.000 & 26.000 & .000 & .851 \\
\hline
\end{tabular}

Tabel 4. Diatas menunjukkan hasil uji multivariate yang menginformasikan bahwa terdapat perbedaan signifikan secara garis besar penurunan suhu tubuh, frekuensi menyusu dan durasi tidur bayi anatara kedua kelompok dengan nilai $F(3.26)=49.334, p<0.001$; Wilk's $\Lambda 0.149, \mathrm{np}^{2}=$ 0.851 .

Tabel 5. Analisis uji Univariat

Tests of Between-Subjects Effects

\begin{tabular}{|c|c|c|c|c|c|c|c|}
\hline Source & Dependent Variable & $\begin{array}{c}\text { Type III Sum of } \\
\text { Squares }\end{array}$ & df & $\begin{array}{l}\text { Mean } \\
\text { Square }\end{array}$ & F & Sig. & $\begin{array}{c}\text { Partial Eta } \\
\text { Squared }\end{array}$ \\
\hline \multirow{3}{*}{$\begin{array}{l}\text { Corrected } \\
\text { Model }\end{array}$} & Suhu Tubuh Bayi & $433.200^{\mathrm{a}}$ & 1 & 433.200 & 151.116 & $.000^{\mathrm{a}}$ & .844 \\
\hline & Frekuensi Menyusu Bayi & $19.200^{\mathrm{b}}$ & 1 & 19.200 & 15.508 & $.000^{\mathrm{b}}$ & .356 \\
\hline & Durasi Tidur Bayi & $16.133^{\mathrm{c}}$ & 1 & 16.133 & 17.554 & $.000^{\mathrm{c}}$ & .385 \\
\hline \multirow{3}{*}{ Intercept } & Suhu Tubuh Bayi & 6278.533 & 1 & 6278.533 & 2190.186 & .000 & .987 \\
\hline & Frekuensi Menyusu Bayi & 282.133 & 1 & 282.133 & 227.877 & .000 & .891 \\
\hline & Durasi Tidur Bayi & 4514.133 & 1 & 4514.133 & 4911.751 & .000 & .994 \\
\hline \multirow{3}{*}{$\begin{array}{l}\text { Metode_} \\
\text { Kangguru }\end{array}$} & Suhu Tubuh Bayi & 433.200 & 1 & 433.200 & 151.116 & .000 & .844 \\
\hline & Frekuensi Menyusu Bayi & 19.200 & 1 & 19.200 & 15.508 & .000 & .356 \\
\hline & Durasi Tidur Bayi & 16.133 & 1 & 16.133 & 17.554 & .000 & .385 \\
\hline \multirow{3}{*}{ Error } & Suhu Tubuh Bayi & 80.267 & 28 & 2.867 & & & \\
\hline & Frekuensi Menyusu Bayi & 34.667 & 28 & 1.238 & & & \\
\hline & Durasi Tidur Bayi & 25.733 & 28 & .919 & & & \\
\hline \multirow{3}{*}{ Total } & Suhu Tubuh Bayi & 6792.000 & 30 & & & & \\
\hline & Frekuensi Menyusu Bayi & 336.000 & 30 & & & & \\
\hline & Durasi Tidur Bayi & 4556.000 & 30 & & & & \\
\hline \multirow{3}{*}{$\begin{array}{l}\text { Corrected } \\
\text { Total }\end{array}$} & Suhu Tubuh Bayi & 513.467 & 29 & & & & \\
\hline & Frekuensi Menyusu Bayi & 53.867 & 29 & & & & \\
\hline & Durasi Tidur Bayi & 41.867 & 29 & & & & \\
\hline
\end{tabular}


Tabel 5. di atas menunjukkan hasil analisis univariat yang menyatakan bahwa perbedaan kelompok menyebabkan perbedaan signifikan pada suhu tubuh $\left[F(1.28)=151.116, p<0.001, \eta^{2}\right.$ $=0.844]$, frekuensi menyusu $\left[F(1.28)=151.116, p=0.000, \mathrm{np}^{2}=0.356\right]$ dan durasi tidur bayi $\left[F(1.28)=151.116, p=0.000, \eta \mathrm{p}^{2}=0.385\right]$. Sehingga perlu dilakukan uji lanjut menggunakan menggunakan koreksi Bonferroni.

Tabel 6. Analisis Uji lanjut Bonferroni

\begin{tabular}{llccccc}
\hline Variabel & Kelompok & Mean & SD & Sig $^{*}$ & \multicolumn{2}{c}{ Notasi BNT } \\
\hline \multirow{2}{*}{ Suhu Tubuh Bayi } & Intervensi & 10.67 & 1.29 & .000 & $\mathrm{a}$ & \\
& Kontrol & 18.27 & 2.01 & .000 & & $\mathrm{~b}$ \\
\hline \multirow{2}{*}{ Frekuensi Menyusu Bayi } & Intervensi & 2.27 & 1.03 & .000 & $\mathrm{a}$ & \\
& Kontrol & 3.87 & 1.18 & .000 & & $\mathrm{~b}$ \\
\hline \multirow{2}{*}{ Durasi Tidur Bayi } & Intervensi & 13.00 & .84 & .000 & $\mathrm{a}$ & \\
& Kontrol & 11.53 & 1.06 & .000 & & $\mathrm{~b}$ \\
\hline
\end{tabular}

Tabel 6. di atas adalah analisis uji lanjut yang dilakukan menggunakan koreksi Bonferroni. Hasil analisis menunjukkan bahwa rerata penurunan suhu tubuh bayi pada kelompok intervensi $(M$ $=10.67, S D=1.29)$ lebih cepat dibandingkan kelompok kontrol $(M=18.27, S D=2.01)$, penurunan tersebut menghsilkan perbedaan yang signifikan $(p<0.001)$. Lebih lanjut, hasil analisis juga menunjukkan bahwa rerata frekuensi menyusu bayi pada kelompok intervensi $(M=2.27, S D=$ 1.03) lebih sering dibandingkan kelompok kontrol $(M=3.87, S D=1.18)$, hal tersebut menghasilkan perbedaan yang signifikan $(p<0.001)$. Hasil analisis juga menunjukkan bahwa rerata durasi tidur bayi pada kelompok intervensi $(M=13.00, S D=0.84)$ lebih lama dan nyaman dibandingkan kelompok kontrol $(M=11.53, S D=1.06)$, keadaan tersebut juga menghasilkan perbedaan signifikan $(p<0.001)$.

\section{Pembahasan}

\section{a. Uji Asumsi One Way MANOVA}

Metode analisis Manova merupakan uji statistik yang diterapkan untuk mengukur pengaruh variabel independen yang berskala kategori terhadap beberapa variabel dependen dengan skala kuantitatif.Analisis Manova dapat dilakukan jika uji asumsi dapat terpenuhi. Salah satu uji asumsi yang dilakukan pada penelitian ini adalah linearitas data menggunakan scatter plot. Pada analisis ini linearitas dimaknai sebagai hubungan antar variabel seperti garis lurus atau membentuk pola garis linear. Berdasarkan grafik 1.Menunjukkan terdapat pola garis lurus antar variabel pada kedua kelompok penelitian, maka dapat disimpulkan bahwa data pada penelitian ini adalah linear.

Analisis uji normalitas data adalah uji asumsi yang ke-2 yang dilakukan pada penelitian ini untuk melihat apakah data suhu tubuh, frekuensi menyusu dan durasi tidur bayi berdistribusi normal pada kedua kelompok penelitian.Penilaian untuk data terdistribusi normal adalah jika nilai $p$ value $>0.05$. Hasil analisis data pada tabel 1 menunjukkan bahwa nilai $p$ value pada kolom signifikansi $>0.05$ baik pada variabel suhu tubuh, frekuensi menyusu maupun durasi tidur, sehingga dapat disimpulkan bahwa seluruh data pada kedua kelompok penelitian terdistribusi normal.

Analisis uji Multikolinearitas adalah uji asumsi ke-3 yang dilakukan pada penelitian ini yang bertujuan untuk mengetahui hubungan antar variabel terikat dalam penelitian ini.Berdasarkan hasil uji asumsi pada tabel 2 didapatkan bahwa suhu tubuh, frekuensi menyusu dan durasi tidur memiliki hubungan yang erat dan kekuatan hubungannya moderat dengan nilai $\mathrm{R}^{2}<0.8$ sehingga dapat disimpulkan gejala multikolinieritas tidak terdeteksi.

Analisis Uji homogenitas data adalah uji asumsi ke-4 yang dilakukan pada penelitian ini dan dari data analisis pada tabel 3 didapatkan nilai Box'M $p<0.001$. Dengan demikian dapat disimpulkan bahwa data pada kedua kelompok dalam penelitian ini homogen.

\section{b. Analisis One Way MANOVA}

\section{Analisis multivariat}

Berdasarkan hasil analisis multivariate pada tabel 4 didapatkan nilai $p$ value $<0.001$ yang artinya terdapat perbedaan signifikan penurunan suhu tubuh, frekuensi menyusu dan durasi tidur pada bayi antara kedua kelompok, sehingga dapat disimpulkan bahwa penurunan suhu tubuh, 
frekuensi menyusu dan durasi tidur pada kelompok intervensi berbeda dengan penurunan suhu tubuh, frekuensi menyusu dan durasi tidur pada kelompok kontrol.

Penelitian ini sejalan dengan penelitian Utami (2015), dimana dari 95 bayi dengan hipotermi ringan setelah dilakukan metode kanguru terjadi peningkatan yang signifikan suhu tubuh bayi sebanyak 54 bayi $(56,8 \%)$ menjadi normal. Hal ini menunjukkan terdapat pengaruh penerapan metode kanguru dengan pencegahan hipotermi pada bayi baru lahir.Hal ini sesuai dengan pendapat, menyatakan bahwa suhu yang optimal pada bayi baru lahir dapat diperoleh dengan adanya kontak langsung antara kulit bayi dengan kulit ibunya.

Penelitian ini juga sejalan dengan penelitian yang dilakukan oleh Felina dan Husniati (2019) yang menyatakan bahwa terdapat perbedaan rerata frekuensi menyusu bayi dengan berat lahir rendah sebelum diberikan PMK dan setelah diberikan PMK menjadi 7 kali dalam 24 jam dengan nilai $p$ value 0.006 yang artinya ada pengaruh PMK terhadap frekuensi menyusu pada bayi.

Penelitian ini juga sejalan dengan penelitian Qor'ila (2017) tentang efektifitas perawatan metode kangaroo terhadap kualitas tidur pada bayi berat lahir rendah kualitas tidur sebelum PMK pada hari ketiga sebanyak 28 (93.3\%) sedangkan kualitas tidur setelah PMK sebanyak 27 (90\%).

\section{Analisis Uji Univariat}

Berdasarkan hasil analisis uji univariat pada tabel 5 menjelaskan bahwa perbedaan kelompok pada penelitian ini menyebabkan perbedaan penurunan suhu tubuh, frekuensi menyusu dan durasi tidur yang bermakna dilihat dari nilai $p$ value $<0.001$. Maka dapat disimpulkan bahwa metode kangguru berpengaruh terhadap penurunan suhu tubuh, frekuensi menyusu dan durasi tidur bayi secara bermakna.

Uji lanjut menggunakan koreksi Bonferroni juga dilakukan pada penelitian ini untuk mengetahui besarnya perbedaan secara bermakna penurunan suhu tubuh, frekuensi menyusu dan durasi tidur antara kelompok intervensi dan kelompok kontrol.Dari hasil uji lanjut juga didapatkan hasil bahwa terdapat perbedaan secara bermakna dengan nilai $p$ value $<0.001$. Sehingga dapat disimpulkan bahwa Penurunan suhu tubuh pada kelompok intervensi 7-8 jam lebih cepat dibandingkan kelompok kontrol. Frekuensi menyusu bayi pada kelompok intervensi 1-2 kali lebih sering dibandingkan kelompok kontrol. Dan durasi tidur bayi pada kelompok intervensi 1,4 kali lebih lama dibandingkan kelompok kontrol.

Menurut asumsi peneliti hal ini dapat terjadi karena penatalaksanaan metode kangguru yang dilakukan dengan baik sangat memberikan manfaat yang besar baik pada ibu dan bayi, salah satunya melalui upaya skin to skin antara ibu dan bayi secara bersamaan dapat menjadi termoregulasi bagi bayi yang mengalami demam ataupun hipotermi untuk kembali pada suhu yang normal, selain itu frekuensi menyusu bayi juga meningkat lebih sering karena dampak rasa nyaman yang ada pada bayi membuat bayi ingin menyusu dan berada di dekapan ibu, dan dari frekuensi menyusu yang baik juga membuat bayi kenyang dan mudah tidur dan istirahat dalam dekapan ibu yang nyaman.

\section{Kesimpulan}

Berdasarkan hasil analisis yang sudah dilakukan maka hipotesis penelitian ini dapat diterima yang artinya ada pengaruh metode kangguru terhadap penurunan suhu tubuh, frekuensi menyusu dan durasi tidur pada bayi.Sehingga metode kangguru tidak hanya dapat diterapkan pada bayi dengan berat lahir rendah tetapi juga dapat diterapkan pada perawatan bayi normal yang mengalami demam, kesulitan menyusu, dan durasi tidur yang tidak baik.

\section{Ucapan Terima Kasih}

Terima kasih kepada Kementerian Pendidikan dan Kebudayaan (KEMENDIKBUD) dan kepada Lembaga Layanan Pendidikan Tinggi Wilayah I (LLDIKTI) serta Pimpinan Puskesmas Bandar Khalipah dan seluruh tenaga kesehatan yang ada dilokasi penelitian. Dengan adanya bantuan dari semua pihak, penelitian ini dapat berlangsung dengan baik semoga hasil penelitian ini dapat bermanfaat untuk masyarakat khususnya ibu dan bayi. 


\section{Referensi}

[1] Proverawati A, Citra Andhini. Buku Imunisasi dan Vaksinasi. Edisi 2. Jakarta. Nuha Medika. 2010.

[2] Lisnawati, Lilis. Generasi Sehat Melalui Imunisasi. CV. Trans Info Media: Jakarta. 2011.

[3] Deslidel, et. al. Buku Ajar asuhan Neonatus, Bayi Dan Balita. Jakarta: EGC. 2011.

[4] Marimbi. Tumbuh Kembang, Status Gizi dan Imunisasi Dasar pada Balita. Yogyakarta: Nuha Medika. 2010.

[5] Atika. Imunisasi dan Vaksinasi. Bantul, Yogyakarta dan Nuha Medika. 2010.

[6] Majiidsumardi. Demam dan Febris. Jakarta. 2011.

[7] Lawn, J. E. et al. Kangaroo mother care to prevent neonatal deaths due to preterm birth complications", 39(I), pp. 144-154. doi: 10.1093/ije/dyq031. 2011.

[8] Mardi Asih Sri Hartini, Wanda Dessie, R.Y. Jurnal Keperawatan dan Kebidanan (JIKK). Semarang: Junal Keperawatan dan Kebidanan (JIKK), I(9), pp. 505-515. Available at: http://ejournal.stikestelogorejo.ac.id /index.php/jikk/article/view/329. 2013.

[9] Deswita, Besral, R. Y. Pengaruh Perawatan Metode Kanguru terhadap Respons Fisiologis Bayi Prematur The Influence of Kangaroo Mother Care on Physiological Response of Premature Infants. Jurnal Kesehatan Masyarakat Nasional, 5(156), pp. 227-233. doi: DOI: http://dx.doi.org/10.21109/kesmas. v5i5.131. 2011.

[10] Mutia Felina dan Nofila Husniati. Pengaruh Perawatan Metode Kangguru Terhadap Frekuensi Menyusu Bayi Berat Badan Lahir Rendah. Jurnal Kesehatan Volume 10 No.2 (2019) 121-127. 2019.

[11] Maryunani A, Eka P., Asuhan Kegawatdaruratan Maternal dan Neonatal. Jakarta: Trans Info Media. 2013.

[12] Heni P \& Widuri. Pengaruh Skin to Skin (PMK) Terhadap Penurunan Suhu Tubuh Pada Bayi Demam. Jurnal Perawat Indonesia. Volume 3 No 1. 2019.

[13] Sherwood L. Fisiologi manusia dari sel ke sistem. 6th ed. Jakarta: EGC; 2012.

[14] Mardiyaningsih, Eko. Efektifitas kombinasi teknik marmet dan pijat oksitosin terhadap produksi asi ibu post seksio sesarea. 2010.

[15] Risma. A.F\& Linda. M. Efektifitas Perawatan Metode Kangguru Terhadap Kualitas Tidur Pada Bayi Berat Lahir Rendah (BBLR) di RSUD Provinsi NTB Tahun 2017. Jurnal Midwifery Update (MU). http://jurnalmu.poltekkes-mataram.ac.id/index.php/jurnalmu. 2017.

[16] Suwanda. Desain Eksperimen untuk Penelitian Ilmiah.Bandung : Alfabeta. 2011.

[17] Widarjono, Agus. Analisis Multivariate Terapan, Edisi Kedua, UPP STIM YKPN: Yogyakarta. 2015. 